MATEC Web of Conferences 33, 04001 (2015)

DOI: $10.1051 /$ matecconf/ 20153304001

(C) Owned by the authors, published by EDP Sciences, 2015

\title{
Hardness-gradient reversion in FeMnSiCr shape memory alloy modules produced by high-speed high pressure torsion
}

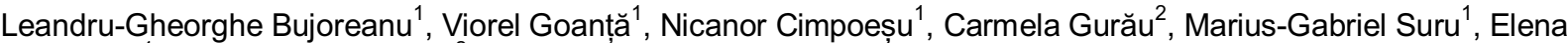 \\ Mihalache ${ }^{1}$ and Gheorghe Gurău 2 ,a \\ ${ }^{1}$ Faculty of Materials Science and Engineering, "Gheorghe Asachi" Technical University of laşi, Blvd. D. Mangeron 61A, 700050 laşi, \\ Romania \\ ${ }^{2}$ Faculty of Engineering, "Dunărea de Jos” University of Galati, Str. Domnească 111, 800201, Galați, Romania
}

\begin{abstract}
High pressure torsion (HPT) processing technology, consisting in the obtainment of (ultra)fine bulk metallic structure during 2-3 complete rotations of the superior anvil at low speed $\left(\sim 10^{-1} \mathrm{rpm}\right)$ under high applied pressure $(\sim \mathrm{GPa})$ applied on the lower anvil, has been modified as to allow the application of elevated number of rotation numbers $\left(\sim 10^{2} \mathrm{rpm}\right)$. By high-speed high pressure torsion (HS-HPT), coned-disk spring shape modules were processed from an as cast $\mathrm{Fe}-28 \mathrm{Mn}-6 \mathrm{Si}-5 \mathrm{Cr}$ (mass \%) shape memory alloy (SMA). Scanning electron microscopy (SEM) and X-ray diffraction (XRD) studies revealed that the modules became nanostructured as an effect of HS-HPT processing. After processing, a hardness gradient was obtained along the truncated cone generator, increasing from inner to outer areas, due to different deformation degrees in these zones. After complete flattening, the measurements revealed that the hardness gradient maintained its value but reversed its variation sense.
\end{abstract}

\section{Introduction}

Amongst intelligent materials, shape memory alloys (SMAs) are characterized by the ability to recover from being deformed, when heated [1]. Commercial SMAs can be classed into three major groups: $\mathrm{Cu}$-based (mainly $\mathrm{CuZnAl}$ and $\mathrm{CuAlNi}$ ), NiTi-based, and Fe-based (e.g., $\mathrm{FeMnSi}, \mathrm{FeNiC}$ and FeNiCoTi) [2].

FeMnSi base Shape Memory Alloys (SMAs) have been developed since the years 1980s [3], as cheap substitutes of Ti-Ni base SMAs [4] and became commercially available under the form of Fe-28 Mn- 6 Si$5 \mathrm{Cr}$ [5] and Fe-14 Mn-5 Si-9 Cr-5 Ni [6] (mass. \%, as all compositions will be listed hereinafter), which have been successfully used for constrained recovery [7] applications.

In FeMnSi based SMAs, $\varepsilon$ hexagonal close-packed (hcp) martensite is stress-induced, by plastic deformation, from $\gamma$ face-centered cubic (fcc) austenite and reverts to the parent phase, by heating, while recovering its initial undeformed macroscopic shape, providing the applied strain does not exceed $5 \%$ [8] and no $\alpha$ ' body centered cubic (bcc) martensite was thermally or stress induced [9].

In order to obtain a large value of shape memory effect (SME), with recoverable strains larger than $4 \%$, $\varepsilon$ hcp stress-induced martensite plates should be as narrow as possible, with a single variant orientation and should interact neither with each other nor with pre-existing thermally or stress-induced martensite [10]. Aiming to reduce austenite grain size and the dimension of

\footnotetext{
${ }^{\mathrm{a}}$ Corresponding author: gheorghe.gurau@ugal.ro
}

martensite plates, various processing routines were tested on FeMnSi SMAs obtained both by conventional technologies (casting and plastic deformation) and by non-conventional ones. For instance, conventionally processed alloys were subjected to various thermomechanical treatments, meant to control the formation [11] and alignment [12] of second-phase precipitates. Conversely, powder metallurgy (PM) processing [13] and severe plastic deformation (SPD) [14] demonstrated their potential to improve the properties of FeMnSi-based SMAs. Thus, PM associated with mechanical alloying (MA) caused FeMnSi-based SMAs with better mechanical [15] and shape memory [16] properties, as compared to conventionally processed alloys.

A special attention has been recently paid to the possibility to obtain nanostructured FeMnSi-based SMAs by means of High Pressure Torsion (HPT), a SPD procedure which has been modified as to allow the application of elevated number of rotation numbers $\left(\sim 10^{2}\right.$ rpm) concomitant with high applied pressure $(\sim \mathrm{GPa})$ [17]. The new procedure, named high-speed highpressure torsion (HS-HPT), was used to produce modules under the form of truncated cone shells, directly from ascast SMAs [18].

The present paper aims to further investigate the response of HS-HPT modules during compression cycles, between flat surfaces, both without and with lubrication, and to corroborate the changes in hardness variation along cone generator with accompanying microstructural changes. 


\section{Experimental}

Fig. 1 presents details of HS-HPT technology and modules geometry. The billets were circular crowns cut from drilled Fe-28Mn-6Si-5Cr SMA ingots.
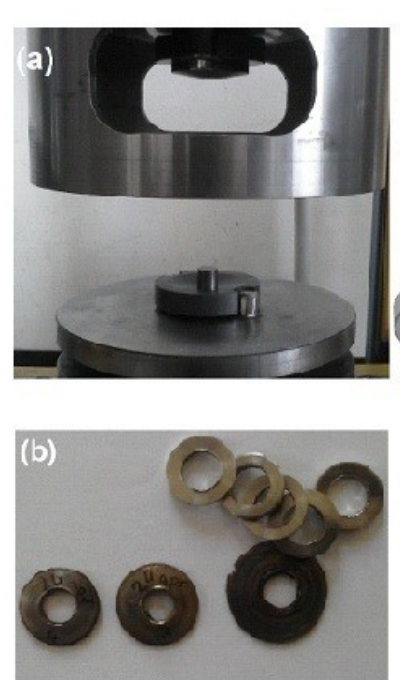

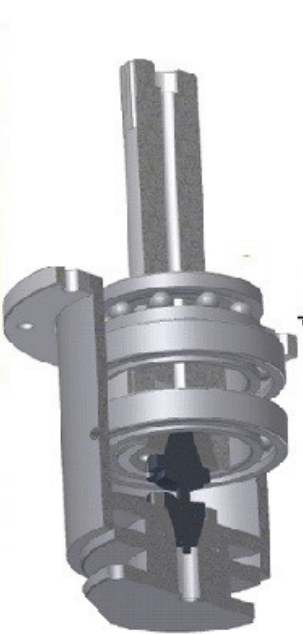

(c)

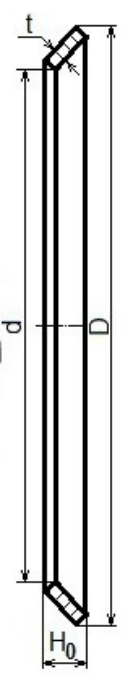

(d)
Figure 1. Details of HS-HPT processing technology: (a) view of the machine, with upper and lower anvils; (b) circular crown billets and truncated cone shape modules (down); (c) schematic section with tool positioning within the assembly; (d) schematic cross-section of module's geometry.

After HS-HPT processing, Vickers Hardness measurements were done according to Fig. 2.

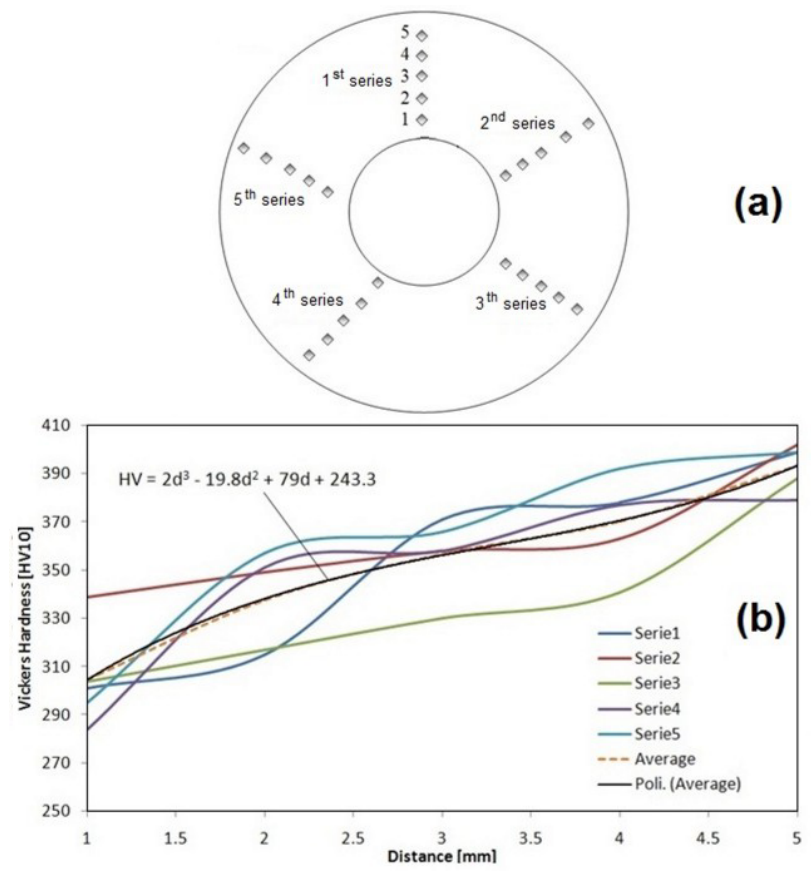

Figure 2. Vickers Hardness gradient after HS-HPT processing: (a) measurement scheme; (b) HV variation, increasing from inner to outer diameters.

HV variation, illustrated in Fig.2(b), reveals an average hardness gradient of $22 \mathrm{HV} / \mathrm{mm}$, increasing from inner to outer diameter zones. This characteristic could be an effect of irregularly distributed flow, during plastic deformation, causing larger deformation degrees, therefore larger work hardening, in the outer areas of the modules. After processing, the modules were machined, so as to adjust and to render parallel upper and lower surfaces [14]. Each module can be described by its shape characteristic ratio:

$$
\text { SCR: }\left(H_{0^{-}} t\right) / t
$$

where $\mathrm{H}_{0}$ and $\mathrm{t}$ are the initial height and the wall thickness of the modules, according to the quarter section shown in Fig. 1(c).

The modules were further subjected to loadingunloading compression tests, performed between flatsurface deformation devices, without lubrication on an INSTRON 3382 testing machine with thermal chamber and with lubrication on an INSTRON 8801 testing machine. In the case of dry-compression tests, the modules were additionally heated, in partially compressed condition, and the variation of constrained recovery force was registered as a function of temperature. In order to obtain an accurate variation of compressive load, as a function of stroke and temperature, the load values corresponding to compression device heating were subtracted from the force values recorded during constrained recovery tests.

The structural changes caused by: (i) HS-HPT processing, (ii) compression and (iii) heating, respectively, were analyzed by X-ray diffraction (XRD), optical (OM) and scanning electron microscopy (SEM) observations. For this purpose, modules in the three above conditions were embedded into cold mounting acrylic resin, before being ground, polished and etched for metallographic analysis.

\section{Experimental results and discussion}

Three modules with SCR of $0.5 ; 1.1$ and 2.8 were subjected to loading-unloading tests, performed by compression between dry flat surfaces and the resulting stroke-load-response is shown in Fig.3. The compressive load vs. stroke variations display, in Fig.3(a), load plateaus, both during loading and unloading, which define the "superelastic-like" response of HS-HPT modules.

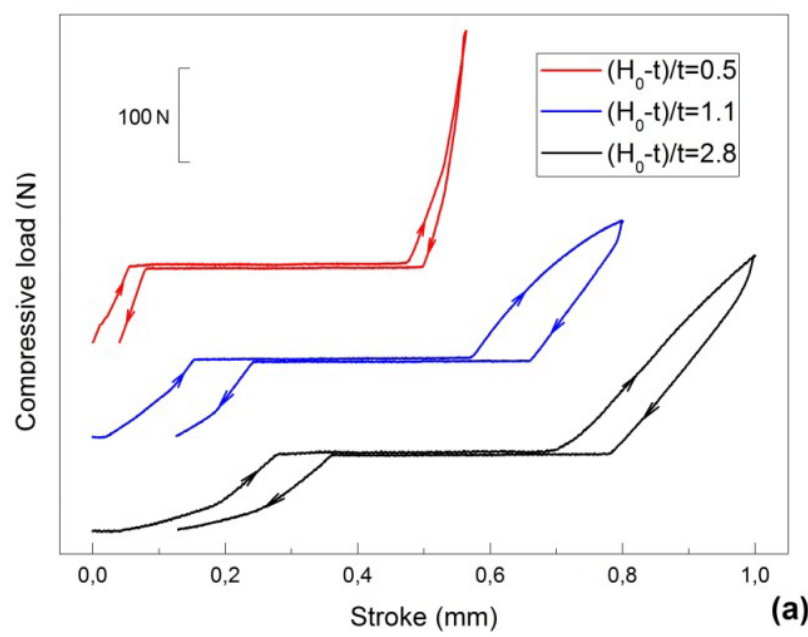




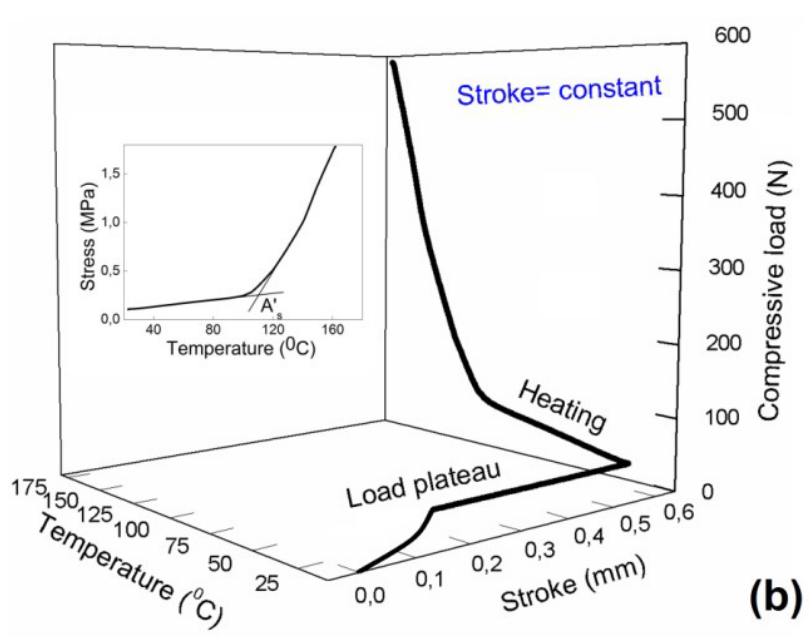

Figure 3. Stroke-load-response of the modules compressed between dry flat surfaces: (a) during room temperature loadingunloading of modules with different shape characteristic ratios (SCR); (b) stroke-load-temperature variation for a module with $\mathrm{SCR}=2.8$, during a constrained recovery test

These plateaus can be associated with the hardness gradient, which enables the gradual bending along cone's generator, from inner to outer diameter area.

In Fig.3(b), the presence of constrained recovery SME was revealed by incomplete pressing of a module with $\mathrm{SCR}=2.8$, holding the module in deformed state at a constant stroke of approx. $0.6 \mathrm{~mm}$, and heating it up to $170^{\circ} \mathrm{C}$, in the thermal chamber of the testing machine. It is noticeable that compressive load reached $600 \mathrm{~N}$, a value much larger than the maximum values obtained, in Fig.3(a), during compression loading. The inset of Fig.3(b) enables to observe stress variation with temperature and the determining procedure of the critical temperature of the start of martensite reversion to austenite, $\mathrm{A}_{\mathrm{s}}=110^{\circ} \mathrm{C}$, by means of tangent method.

For wet-compression tests, stress was determined by dividing compressive load to the projection area of flattened module $\left(\pi\left(\mathrm{D}^{2}-\mathrm{d}^{2}\right) / 4\right.$ while strain was the ratio between stroke and wall thickness (t). Since the height is $\mathrm{H}_{0}>\mathrm{t}$, strain values exceed $100 \%$, as in Fig.4, for a module with $\mathrm{SCR}=2.2$.

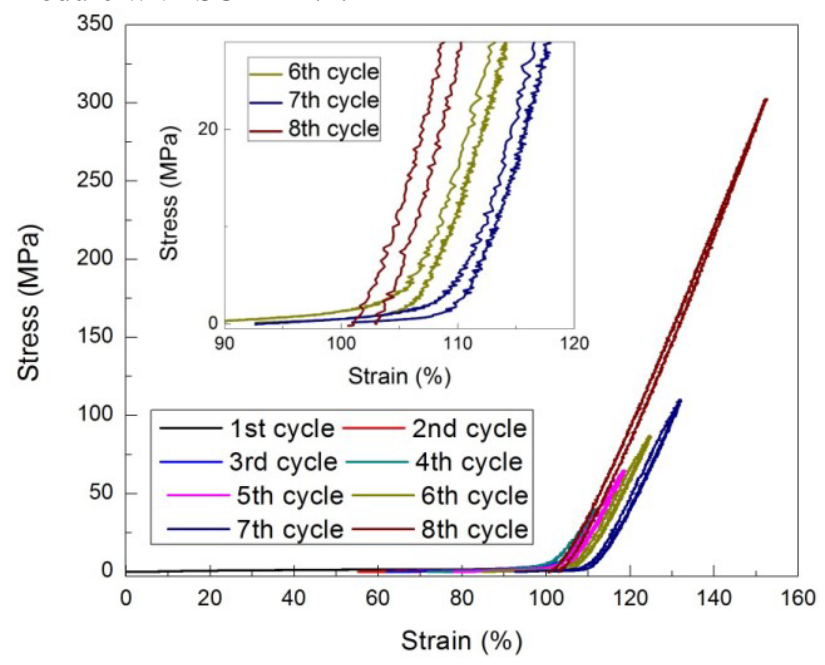

Figure 4. Stress-strain variations during wet-compression loading-unloading cycles of a module with $\mathrm{SRC}=2.2$.
During wet-compression testing, of FeMnSiCr SMA modules obtained by HS-HPT, two distinct portions of the stress-strain curves are obvious: (i) an initial portion with reduced slope, corresponding to module's elastic flattening and (ii) a final high-slope portion corresponding to material's hydrostatic compression. It can be assumed that the former region was caused by module's geometry and the latter by module's material. In contrast to dry-compression tests, from Fig.3(a) in Fig.4 no gradual bending occurred, since the module was allowed to slip, with regards to the flat-compression surface. During the first seven cycles, the compressive stress experienced three tendencies: 1) to increase slowly, during module's elastic flattening, suggesting the rotation of entire cross-section, as in the case of disk springs [19]; 2) to augment abruptly during hydrostatic compression and 3) to spring-back additionally during unloading.

When expressing recoverable strain as the ratio between unloading and loading strains, the following percent values are obtained for Shape Recovery Degree (SRD), with increasing the number of cycles: $1^{\text {st }}-61.4$ $\% ; 2^{\text {nd }}-82.4 \% ; 3^{\text {rd }}-76.2 \% ; 4^{\text {th }}-83.5 \% ; 5^{\text {th }}-84.3 \%$; $6^{\text {th }}-81.5 \% ; 7^{\text {th }}-78.9 \%$ and $8^{\text {th }}-95.9 \%$, so there is an obvious increasing tendency of SRD, during mechanical cycling, which can be considered as a training effect [20]. Another variation tendency, noticeable with the increase of the number of mechanical cycles, is the gradual diminution of the elastic low-slope portion, which suggests that the module loses its elastic spring-back capacity and becomes more and more flat, with the increase of the number of cycles. After 7 wetcompression loading-unloading cycles, module's height was reduced with $100 \%$ (as compared to wall thickness) and for this reason, stress variation in the 8 th cycle is completely different. The inset of Fig.4 illustrates the 6th to 8th wet-compression loading-unloading cycles. It is obvious that in the 8 th cycle the module is completely flat, so that only the second portion of the curve, corresponding to hydrostatic pressing, is noticeable.

After complete flattening as an effect of wetcompression, the modules were removed from the testing machine and HV measurements were resumed, according to the same measuring scheme as in Fig.2(a). The results are shown in Fig.5, along with the polynomial fit of HV variation with distance.

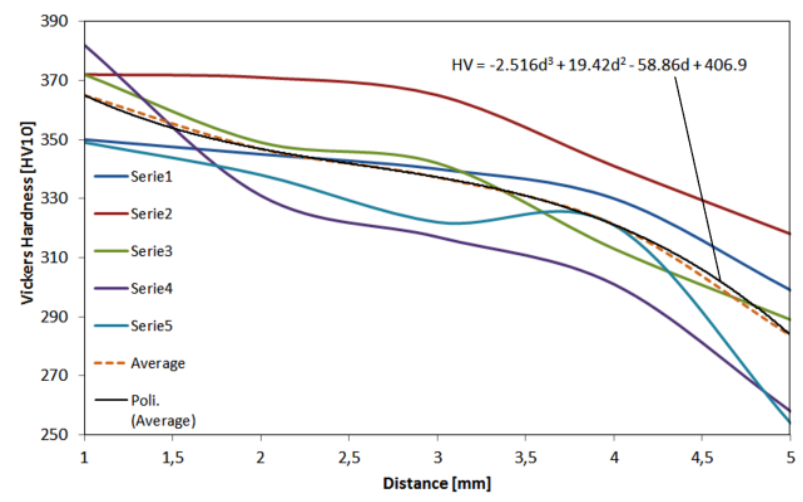

Figure 5. HV variation, after complete wet-compression flattening, revealing hardness gradient reversion, as compared to initial state, shown in Fig.2, after HS-HPT processing. 
In this case, there is a hardness gradient with the average value of $20 \mathrm{HV} / \mathrm{mm}$. Its sense, is opposite as compared to Fig.2(b) since it decreases from inner to outer diameter zones. So, after eight wet-compression loading-unloading cycles, which caused module's complete flattening, the hardness gradient, along module's cone generator reversed its sense. One possible explanation for this drastic change can be related to the more intense work hardening of inner areas, which were repetitively deformed according to the low-slope portions of Fig.4.

Aiming to observe the structure of the modules after HS-HPT processing and the structural changes induced by compression and subsequent heating, metallographically prepared specimens corresponding to initial, compressed and heated states, respectively, were analyzed by XRC, OM and SEM.

The recorded XRD patterns are illustrated in Fig.6, together with details of the evolution of main diffraction maxima, of the three phases: $\gamma$-fcc austenite, $\varepsilon$-hcp martensite and $\alpha$ '-bcc martensite.
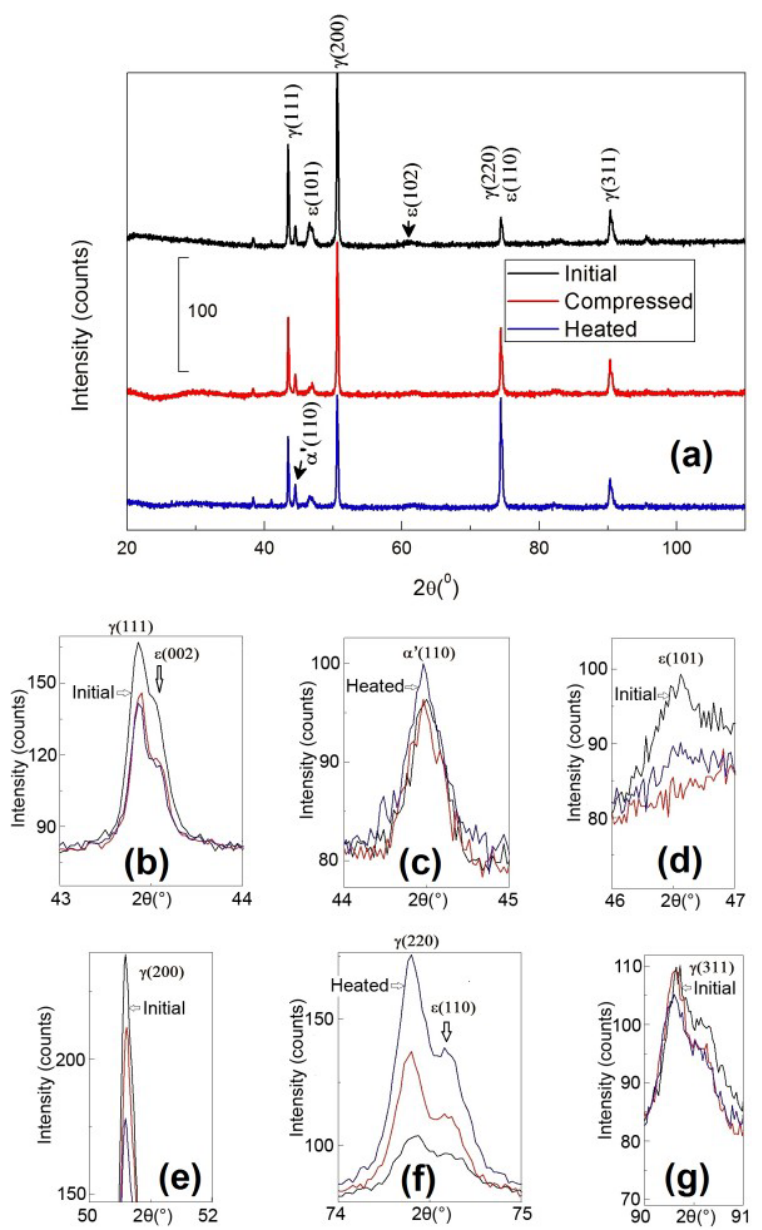

Figure 6. XRD patterns of the modules in initial, compressed and heated conditions: (a) complete records and details of main diffraction peaks: (b) $\gamma(111)$; (c) $\alpha^{\prime}(110)$; (d) $\varepsilon(101)$; (e) $\gamma(200)$; (f) $\gamma(220) / \varepsilon(110) ;($ g) $\gamma(311)$.

Since the modules obviously experienced constrained recovery SME, the stress-induced formation of $\varepsilon$-hcp martensite and its thermally induced reversion to $\gamma$-fcc austenite would be expectable, after plastic deformation and heating, as it is the case of common FeMnSiCr SMAs [21]. For crystallographic calculations, the parameter of fcc unit cell of $\gamma$ austenite was considered as $\mathrm{a}_{\gamma}=0.36 \mathrm{~nm}$, while the parameters of hexagonal unit cell of $\varepsilon$ martensite have been $\mathrm{a}_{\varepsilon}=0.254 \mathrm{~nm}$ and $\mathrm{c}_{\varepsilon}=0.4 \mathrm{~nm}$ [22]. Due to the elevated levels of micro-strains, caused by HS-HPT processing, $\alpha$ ' martensite was observed, its bcc unit cell having the parameter $\mathrm{a}_{\alpha^{\prime}}=0.287 \mathrm{~nm}$ [23]. On the recorded XRD patterns, $\gamma$-fcc austenite, was identified with the crystallographic maxima (111), (200), (220) and (311), \&-hcp martensite was represented by its close packed planes (002), (101) and (110) and $\alpha^{\prime}$-bcc martensite by its main diffraction maximum of (110).

In the case of present modules, processed by HSHPT, due to the elevated amounts of pressure and torsion a part of the material became nanostructured. This statement is valid especially in the case of $\varepsilon$-hcp martensite plate variants. Some of their corresponding XRD peaks became distorted and round. These broader peaks are indicative of the existence of either small $\varepsilon$-hcp martensite crystallite size along the direction normal to the specified planes or of distortion (micro-strains) of the crystal structure. For this reason, the position of $\varepsilon(102)$ peak was only indicated in Fig.6(a). On the other hand, Fig.6(d) clearly illustrates the details of very deformed diffraction maxima corresponding to $\varepsilon(101)$ martensite plate variant.

The summary of XRD peak analysis is shown in Table 1, which contains both the values of $2 \theta$ angles and Miller indices from crystallographic databases and the experimental results of quantitative analysis performed by XRD peak planimetric measurements.

Table 1. Quantitative structural analysis based on XRD patterns of Fig.6.

\begin{tabular}{|c|c|c|c|c|c|c|c|}
\hline \multicolumn{3}{|c|}{ Crystallographic dabases } & \multicolumn{4}{|c|}{ Results } \\
\hline \multirow{2}{*}{$2 \boldsymbol{2 0}(\boldsymbol{0})$} & \multicolumn{2}{|c|}{$\begin{array}{c}\text { Miller } \\
\text { indices }\end{array}$} & \multirow{2}{*}{ Phase } & \multicolumn{3}{|c|}{ Relative amount (\%) } \\
\cline { 2 - 4 } & $\boldsymbol{h}$ & $\boldsymbol{k}$ & $\boldsymbol{l}$ & & initial & compressed & heated \\
\hline 43.608 & 1 & 1 & 1 & $\gamma$-fcc & 13.69 & 8.54 & 6.01 \\
\hline 44.381 & 0 & 0 & 2 & $\varepsilon$-hcp & 8.99 & 4.04 & 2.87 \\
\hline 44.485 & 1 & 1 & 0 & $\alpha$ '-bcc & 3.28 & 3.9 & 4.88 \\
\hline 47.041 & 1 & 0 & 1 & $\varepsilon$-hcp & 10.05 & 6.2 & 5.47 \\
\hline 50.795 & 2 & 0 & 0 & $\gamma$-fcc & 43.97 & 43.46 & 33.43 \\
\hline 74.681 & 2 & 2 & 0 & $\gamma$-fcc & 4.82 & 14.37 & 24.42 \\
\hline 75.025 & 1 & 1 & 0 & $\varepsilon$-hcp & 4.04 & 8.41 & 14.91 \\
\hline 90.673 & 3 & 1 & 1 & $\gamma$-fcc & 11.16 & 11.07 & 8.01 \\
\hline
\end{tabular}

The results of quantitative analysis, listed in Table 1, show that, during different processing steps, the texture of modules microstructure changed. The global amounts of $\gamma$-fcc austenite, $\varepsilon$-hcp martensite and $\alpha^{\prime}$-bcc martensite varied as follows:

1.in initial condition $74 \% \gamma, 23 \% \varepsilon$ and $3 \% \alpha^{\prime}$;

2. in compressed state $77 \% \% \gamma, 19 \% \varepsilon$ and $4 \% \alpha$ '

3. in heated condition $72 \% \gamma, 23 \% \varepsilon$ and $5 \% \alpha$ '.

These results suggest that, at the end of a compression-heating cycle, a small amount of austenite irreversibly transformed to $\alpha$ '-bcc martensite.

For a better insight of the evolution of metallographic phases, microscopic analyses were performed by OM and SEM, the results being illustrated in Fig. 7. 


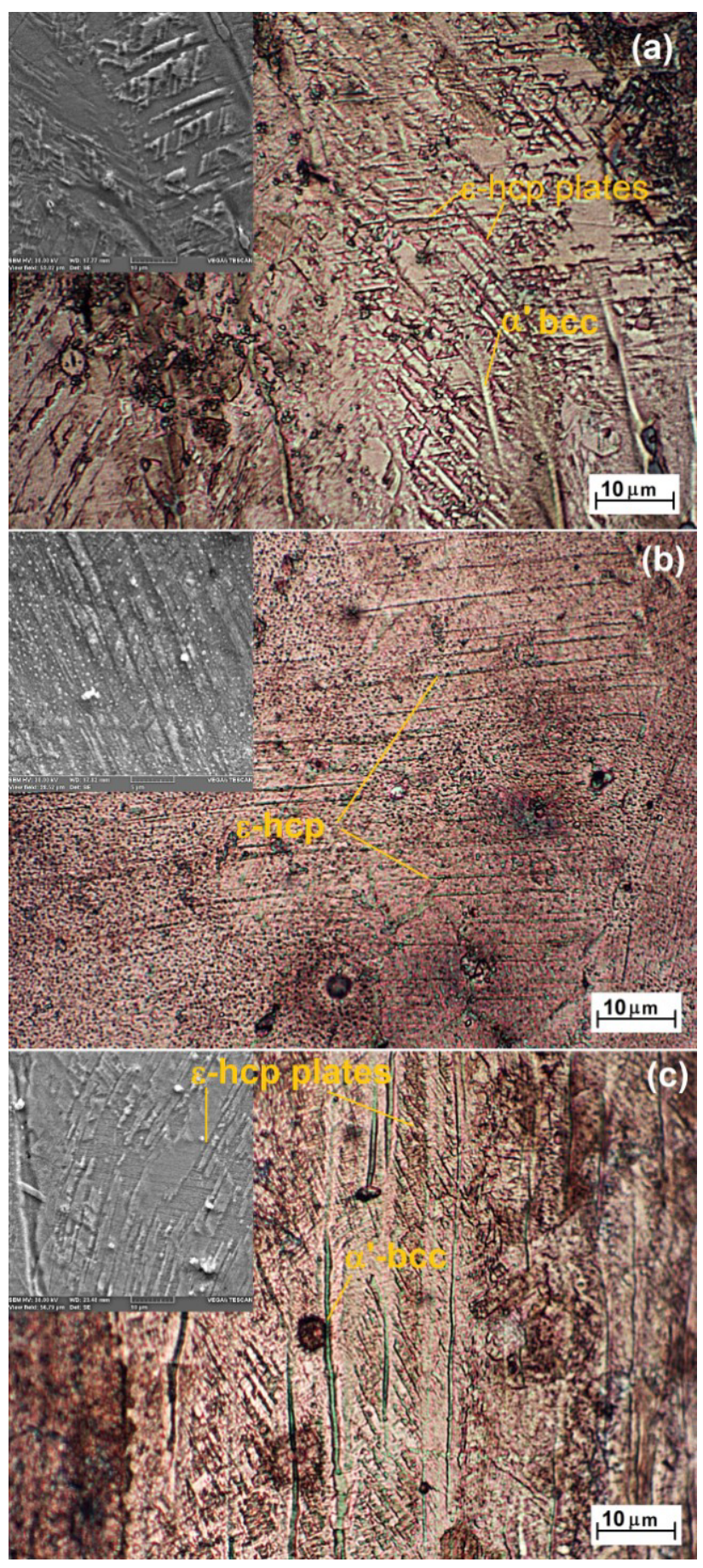

Figure 7. OM micrographs with SEM insets illustrating the microstructure of HS-HPT modules in different conditions: (a) initial state, with narrow plates of $\varepsilon$-hcp martensite and wide $\alpha$ bcc martensite bands; (b) compressed state, with narrow evenly spaced $\varepsilon$-hcp martensite plates; (c) heated state, with shorted $\varepsilon$ plates and long $\alpha$ ' bands.

It is well-known that, in FeMnSi SMAs, $\varepsilon$-hcp martensite has typical "triangular" morphology, due to its habit planes of $\{111\} \gamma$ type [24]. Its plates are generally narrow and completely cross austenite grains, from one border to the other. On the other hand, $\alpha^{\prime}$-bcc martensite, which typically forms at low Mn contents or at high stress amounts, has the form of wider bands with lenticular shape, which do not cross austenite grains [25]. These aspects are less visible in Fig.7, since the alloys under study underwent severe plastic deformation which drastically altered the crystalline structure. Thus, it is noticeable that the microstructure of the module in initial HS-HPT processed state, Fig.7(a), is heavily distorted and comprises fine interlocking $\varepsilon$-hcp martensite plates, with sub-micrometer widths. In addition, the plates have only two $\{111\}$ orientations, in such a way that the "triangular" morphology is not noticeable.

On the other hand, $\alpha$ '-bcc martensite plates are thicker and longer, being better emphasized in initial and heated states. After compression, Fig.7(b) illustrates the development of parallel arrays of $\varepsilon$-hcp martensite plates, which became thinner as compared to initial condition. This refining tendency of martensite plates, after compression, was also observed in conventionally processed FeMnSi SMAs [26]. After heating, long $\alpha$ '-bcc martensite plates were developed, in Fig.7(c), which fragment the fine $\varepsilon$-hcp martensite plates. In all of the three micrographs, the structure is highly distorted.

\section{Summary and conclusions}

Truncated cone disc spring-shape modules, with different shape characteristic ratios (SCR), were processed, from as-cast Fe-28Mn-6Si-5Cr (mass. \%) SMAs, by means of high speed-high pressure torsion.

HS-HPT processing caused the occurrence of a hardness gradient, of approx. $22 \mathrm{HV} / \mathrm{mm}$, increasing along cone's generator, from inner to outer diameter areas. After complete flattening, by wet-compression between plane surfaces, the hardness gradient reversed its variation sense, increasing from outer to inner diameter areas, with an average value of $20 \mathrm{HV} / \mathrm{mm}$.

During compression loading-unloading cycles, performed without lubrication between flat surfaces, the following variation tendencies were observed:

- the modules experience a "superelastic-like" response, with force plateaus, both on loading and unloading;

- the force plateaus can be associated with the impossibility of inner diameter areas, of tested modules, to slip with regards to the flat compression surface, so they gradually bend along cone generator, as predicted by FEM simulations [27];

- stroke magnitude experienced an increasing tendency with increasing SCR value;

- when heated in compressed state, the modules developed constrained recovery forces larger than those reached during isothermal compression loading.

After compression loading-unloading cycles, performed with lubrication between flat surfaces, the modules cross-section was allowed to rotate, being twisted in the same way as disk springs are [19] and the following tendencies were observed in stress-strain variation:

- it had a double slope both on loading and unloading and an obvious pseudoelastic character, which experienced a decreasing tendency with increasing the number of cycles;

- shape recovery degree increased with the number of cycles. 
By XRD, OM and SEM observations, the following conclusions were obtained:

- in initial state, only two $\varepsilon$-hcp martensite plate variants were noticeable;

- some $\varepsilon$-hcp martensite plate variants were highly distorted;

- long $\alpha^{\prime}$-bcc martensite plates were developed.

\section{Acknowledgements}

This research work was supported by UEFISCDI through project code PN.IIPT-PCCA-2011-3.1-0174, Contract 144/2012.

\section{References}

1. J. Ma, I. Karaman, Science 327, 1468 (2010)

2. L. Sun, W.M. Huang, Z. Ding, Y. Zhao, C.C. Wang, H. Purnawali, C. Tang, Mater. Design 33, 577 (2012)

3. A. Sato, E. Chishima, K.Soma, T.Mori, Acta Metall. 30, 1177 (1982)

4. R. D. James, K. F. Hane, Acta Mater. 48, 197 (2000)

5. H. Otsuka, H. Yamada, T. Maruyama, H. Tanahashi, S. Matsuda, M. Murakami, ISIJ Int. 30, 674 (1990)

6. Y. Moriya, H. Kimura, S. Ishizaki, S. Hashizume, S. Suzuki, H. Suzuki and T. Sampei, "Properties of FeCr-Ni-Mn-Si (-Co) shape memory alloys", J Phys IV. 01C4, pp. 433-437, 1991.

7. J.L. Proft, T.W. Duerig, In: Engineering Aspects of Shape Memory Alloys, T.W. Duerig, K.N. Melton, D. Stöckel, C.M. Wayman, (Eds.), ButterworthHeinemann, London, 115 (1990)

8. N. Stanford, D. P. Dunne, H. Li, Scripta Mater. 58, 583 (2008)

9. G.J. Arruda, V.T.L. Buono, M.S. Andrade, Mat. Sci. Eng. A 273-275, 528 (1999)

10. Y.H. Wen, N. Li, L. R. Xiong, Mater. Sci. Eng. A 407, 31 (2005)

11. S. Kajiwara, D. Liu, T. Kikuchi, N. Shinya, Scripta Mater. 44, 2809 (2001)
12. Y. H. Wen, W. Zhang, N. Li, H. B. Peng, L.R. Xiong, Acta Mater. 55, 6526 (2007)

13. B. Pricop, U. Söyler, N.M. Lohan, B. Özkal L.G. Bujoreanu, D. Chicet, C. Munteanu, J. Mater. Eng. Perform. 21, 2407 (2012)

14. G. Gurău, C. Gurău, O. Potecașu, P. Alexandru, L.G. Bujoreanu, J. Mater. Eng. Perform. 23, 2396 (2014)

15. T. Saito, C. Kapusta, A. Takasaki, Mat. Sci. Eng. A 592, 88 (2014)

16. A.U. Söyler, B. Özkal, L.G. Bujoreanu, J. Mater. Eng. Perform. 23, 2357 (2014)

17. G. Gurău, L.G. Bujoreanu, O. Potecașu, N. Cănănău, P. Alexandru, C. Gurău, D. Tănase, Patent application no. a2013 00351, BOPI 11/ 2014.

18. L.G. Bujoreanu, G. Gurău, I. Dan, C. Știrbu, R.I. Comăneci, N.M. Lohan, B. Pricop, A. L. Paraschiv, M.G. Suru, C. Gurău, Patent application no. a2013 00374, BOPI 11/ 2014.

19. Handbook for Disc Springs, Schnorr, DiscSprings_screen searchable.pdf, http://www.schnorr.com, accessed on June the 25th 2014

20. M. Koyama, T. Sawaguchi, K. Ogawa, T. Kikuchi, M. Murakami, Mat. Sci. Eng. A 497, 353 (2008)

21. L. G. Bujoreanu, S. Stanciu, R. I. Comăneci, M. Meyer, V. Dia, and C. Lohan:, J. Mater. Eng. Perform. 18, 500 (2009)

22. B.C. Maji, K. Madangopal, V.V. Rama Rao, Metall. Mater. Trans. 34A, 1029 (2003)

23. T. Kirindi, E. Güler, M. Dikici, J. Alloy. Compd. 433, 202 (2007)

24. S. Kajiwara, Mater. Sci. Eng. A 273-275, 67, (1999)

25. B.C. Maji, K. Madangopal, V. Hiwarkar, I. Samajdar, R.K. Ray, J. Mater. Eng. Perform. 18, 588 (2009)

26. T. Sawaguchi, L.G. Bujoreanu, T. Kikuchi, K. Ogawa, M. Koyama, M. Murakami, Scripta Mater. 59, 826 (2008)

27. L.G. Bujoreanu, R.I. Comăneci, G. Gurău, N.M. Lohan, M.G. Suru, B. Pricop, V. Goanță, V. Mușat, B. Istrate, E. Mihalache, Indian J. Eng. Mater. S. 22, 367 (2015) 